\title{
The operations of the free maternal care policy and out of pocket payments during childbirth in rural Northern Ghana
}

\author{
Philip Ayizem Dalinjong ${ }^{*}$ (D), Alex Y. Wang and Caroline S. E. Homer
}

\begin{abstract}
Background: To promote skilled attendance at births and reduce maternal deaths, the government of Ghana introduced the free maternal care policy under the National Health Insurance Scheme (NHIS) in 2008. The objective is to eliminate financial barriers associated with the use of services. But studies elsewhere showed that out of pocket (OOP) payments still exist in the midst of fee exemptions. The aim of this study was to estimate OOP payments and the financial impact on women during childbirth in one rural and poor area of Northern Ghana; the Kassena-Nankana municipality. Costs were taken from the perspective of women.
\end{abstract}

Methods: Quantitative and qualitative data collection techniques were used in a convergent parallel mixed methods study. The study used structured questionnaire $(n=353)$ and focus group discussions (FGDs $=7$ ) to collect data from women who gave birth in health facilities. Quantitative data from the questionnaire were analysed, using descriptive statistics. Qualitative data from the FGDs were recorded, transcribed and analysed to determine common themes.

Results: The overall mean OOP payments during childbirth was GH $\$ 33.50$ (US\$17), constituting 5.6\% of the average monthly household income. Over one-third $(36 \%, n=145)$ of women incurred OOP payments which exceeded $10 \%$ of average monthly household income (potentially catastrophic). Sixty-nine percent $(n=245)$ of the women perceived that the NHIS did not cover all expenses incurred during childbirth; which was confirmed in the FGDs. Both survey and FGDs demonstrated that women made OOP payments for drugs and other supplies. The FGDs showed women bought disinfectants, soaps, rubber pads and clothing for newborns as well. Seventy-five percent $(n=264)$ of the women used savings, but 19\% had to sell assets to finance the payments; this was supported in the FGDs.

Conclusion: The NHIS policy has not eliminated financial barriers associated with childbirth which impacts the welfare of some women. Women continued to make OOP payments, largely as a result of a delay in reimbursement by the NHIS. There is need to re-examine the reimbursement system in order to prevent shortage of funding to health facilities and thus encourage skilled attendance for the reduction of maternal deaths as well as the achievement of universal health coverage.

Keywords: National Health Insurance, Social health insurance, Universal health coverage, Free maternal care policy, Fee exemption, Out of pocket payments, Skilled attendance, Childbirth, Delivery, Ghana

\footnotetext{
* Correspondence: PhilipAyizem.Dalinjong@student.uts.edu.au

Faculty of Health, University of Technology Sydney, Building 10, Level 7\&8,

Jones Street, Ultimo, PO Box 222, Sydney, NSW 2007, Australia
} 


\section{Background}

Skilled attendance at childbirth has been recommended for the reduction of maternal and newborn deaths [1-3]. A $20 \%$ reduction in stillbirths or maternal deaths is expected when skilled attendants are utilised during childbirth, given the availability of equipment, drugs and supplies [1]. In Ghana, uptake of skilled attendance at childbirth is a challenge, especially for rural populations and poor families. While urban areas and rich families had a skilled attendance coverage of $87.4 \%$ and $90.5 \%$ respectively, rural areas and poor families had a coverage of $57.2 \%$ and $42.1 \%$ respectively [1]. Financial barriers are largely attributable to this phenomenon, as a quarter of Ghanaians are poor, especially rural populations [4].

Making direct out of pocket payments (OOP) can prevent poor households from using maternal health services, including skilled attendance at childbirth [5-7]. Poor households are likely to forgo essential health services when they have to make direct OOP payments. In addition, some households are pushed further into poverty through their use of health services [5]. Empirical evidence points to the positive effects of risk pooling programmes, including fee exemption policies on the use of maternal health services. For example, the implementation of fee exemption policies in particular have led to a decrease in OOP payments for maternal health services [8-12]. Fee exemption policies have also improved the utilisation of skilled attendance at childbirth and reduced maternal deaths $[12,13]$.

To promote skilled attendance at childbirth and reduce maternal deaths in Ghana, a fee exemption policy to cater for pregnant women in the four poorer regions of Central, Northern, Upper East and Upper West was initially implemented in 2003. In 2005, the exemption was extended to the rest of the country. The prime aim of the policy was to remove direct OOP payments associated with the use of maternal health services. Under the policy, metropolitan, municipal and district assemblies were responsible for the reimbursement of health facilities after the provision of maternal health services to women. Nevertheless, governmental budgetary constraints affected the successful implementation of the initiative [14]. The initiative was reintroduced in July 2008 and referred to as the free maternal care policy, operating under the National Health Insurance Scheme (NHIS). Under the policy, pregnant women are entitled to free of charge registration with the NHIS, free of cost health services and drugs up to the time of childbirth and after (90 days). Following the implementation of the policy, studies have shown an increase in coverage for skilled attendance at childbirth [15-19].

However, studies in Africa and Asia have shown that OOP payments still persisted in the midst of fee exemptions policies, especially for skilled attendance at childbirth $[11,20-25]$. This phenomenon is attributed to systemic challenges [14]. In Ghana, the benefit package of the NHIS does not cover the cost of transport and thus pregnant women and expectant mothers would have to pay for transport to and from health facilities under the free maternal care policy. But transport cost is reported to be a major cost driver for the use of maternal health services $[21,26]$. Given this background, there is limited knowledge on costs associated with the utilisation of skilled attendance at childbirth under the free maternal care policy in Ghana. This study therefore aimed to estimate OOP payments during childbirth and the financial impact on women under the free maternal care policy of the NHIS in poor rural Northern Ghana. OOP payments were determined from the perspective of women.

\section{Methods}

Study design

Both quantitative and qualitative data collection techniques were used through a convergent parallel mixed methods design [27]. Convergent parallel mixed methods allows for the convergence or combination of quantitative and qualitative data to ensure a comprehensive analysis of a research question [27]. The study is descriptive in nature. The quantitative component of the study was carried out among women who had given birth in health facilities (facility-based). A structured questionnaire were designed to collect quantitative data including information on OOP payments.

Focus group discussions (FGDs) collected qualitative data among women who had given birth in health facilities. A semi-structured interview guide was developed and used for the FGDs. The quantitative and qualitative data collection took place from March to August, 2016.

\section{Study area}

The Kassena-Nankana municipality is one of three municipalities in the Upper East region of Northern Ghana where the study took place. Over two-thirds of the population are rural, with the majority involved in agricultural activities [28]. The municipality has similar characteristics as other poor areas in other regions of Ghana and Africa. A number of health facilities exist in the municipality including community-based health planning and services (CHPS compounds), clinics, and health centres. The highest point of referral within the municipality is the district hospital located in the capital town, Navrongo. Specifically, the study took place in the district hospital, two (2) health centres and eleven (11) CHPS compounds. These health facilities had at least one midwife and were providing childbirth services in the municipality at the time of the study.

\section{Study population and sampling}

The study population was women who gave birth in health facilities in the study area. The sample size was 
determined through the formula given by Gorstein et al. [29] for a proportion in a single cross-sectional survey. The processes of sample determination for the study has been shown in [30]. This paper used data from three hundred and fifty-three (353) women who gave birth in health facilities (facility-based).

\section{Data collection}

The survey data was captured through structured questionnaire. The data was electronically collected with the use of SurveyCTO Collect v2.10 software application. Survey CTO Collect allows for data capture, transport and processing on hand-held electronic gadgets like tablets and smart mobile phones. Women were identified and recruited daily as they gave birth and were discharged to go home from the study health facilities. Administering of the questionnaire took between 30 and $45 \mathrm{~min}$. The main investigator supervised the data collection which was carried out by research assistants.

\section{Questionnaire instrument}

The questionnaire collected data on the socio-demographic characteristics of the women. Questions on OOP payments including payments to acquire the antenatal record folder, attend antenatal consultation, have laboratory testing, drugs, and blood transfusion were asked. Women were asked about expenditure on food and transportation to and from health facilities. Expenditure for inpatient health services (admissions) were also solicited. An admission was taken to be a stay in a health facility for a period longer than $12 \mathrm{~h}$. Finally, the study collected data on the source of funding for OOP payments. Indirect costs (that is; opportunity costs due to time lost at health facilities) were not assessed due to the challenges associated with the capturing of such data.

\section{The qualitative study}

The study developed and used semi-structured interview guide for the conduct of the focus group discussions (FGDs) with the women. The guide was initially developed in English, focusing on the utilisation of skilled attendance and OPP payments. The guide was translated by experts into the Kasem and Nankam languages spoken in the study area. Back translations were carried out to ensure accuracy of the translations. Overall, seven (7) focus group discussions (FGDs) were held among women who gave birth in health facilities. To ensure women felt free to speak in the FGDs, health providers were not allowed to be present during the discussions. Membership of the FGDs ranged between 5 and 12 .

Permission was obtained from all women for the recording of the discussions and field notes were taken. The FGDs were flexible, allowing the facilitator to follow-up specific areas as well as seek clarifications on emerging issues.
Particularly, all participants were encouraged to participate in the discussions. To validate the data, issues discussed were presented back to participants for their confirmation or rejection at the end of the discussion. In addition, new issues emerging from the discussions were added to the guide for the next round of discussions. The discussions ended (signifying data saturation) when participants had no further responses despite prompts and probes from the investigator. Each FGD lasted 45-120 min. All the FGDs were moderated by the main investigator.

\section{Data analysis and management (quantitative study)}

The analysis was carried out in STATA 14, using descriptive statistics to assist understand the background characteristics and other study variables. The OOP payments were classified as direct medical, direct non-medical and hospitalisation (inpatient). The direct medical expenses (outpatient) comprises of the cost of the antenatal folder, consultation charge, laboratory tests, cost of drugs and blood (for cases of blood transfusion). Direct non-medical expenses included the cost of meals and transportation to and from health facilities. The hospitalisation expenses were for costs incurred as a result of hospital admission (inpatient). The expenditure for inpatient health services comprised of a summation of the costs for medical services, laboratory testing, drugs and bedding during admission. The estimation of the overall mean OOP payments was expressed as $\mathrm{M}=\mathrm{a}+\mathrm{b}+\mathrm{c}$, where $\mathrm{M}=$ overall mean OOP payments, $\mathrm{a}=$ direct medical expenses, $\mathrm{b}=$ direct non-medical expenses, and $\mathrm{c}=$ hospitalisation cost. The direct medical, direct non-medical and hospitalisation costs were estimated by aggregating the costs from which means and standard deviations were determined.

To estimate the impact of OOP payments on women/ households, the overall mean cost was calculated as a percentage of the mean monthly household income of the Upper East region (region of study). Data were not available specifically for the Kassena-Nankana municipality. The average annual household income for the region was GH\$7240.5 (US\$3673.8) as reported in the Ghana Living Standards Survey Report Round 6 [28]. This translated to an average monthly household income of GH\$603.4 (US\$306.2), which was used for the determination of the impact of OOP payments on income of households. OOP payments that are considered to be catastrophic for families were also estimated using the same average monthly household income (GH\$603.4 $=$ US\$306.2). Catastrophic OOP payments are those which disrupt the consumption patterns of households, particularly essential goods and services. Catastrophic OOP payments were considered to have occurred when health expenditure for a given episode were equivalent to or exceeded a set threshold for a household's resource (income or expenditure). Thresholds often vary, ranging from $5 \%$ to $40 \%$ [26, 31- 
33]. This study used a $10 \%$ threshold for the determination of catastrophic OOP payments, as done in other studies [33-35]. Women whose OOP payments exceeded $10 \%$ of the average monthly household income were classified as having made catastrophic OOP payments.

The costs data for the study was reported in Ghana cedis, but converted into US\$, using an exchange rate of US\$1 = GH 1.9708 (2013 exchange rate) as existed in the Ghana Living Standards Survey Report of the sixth round [28]. This is to ensure conformity with the data used from that survey (the Ghana Living Standards Survey).

\section{Data analysis and management (qualitative study)}

All audio tapes were translated verbatim into English. Transcripts and field notes were read a number of times to help understand the patterns in the data before coding. The main investigator also reviewed a number of the audio recordings, comparing to their original transcripts. Any difference observed was corrected before the coding. This activity sought to ensure validity and accuracy in the data collected. A further review of the transcripts was carried out, including hand written notes on the transcripts to bring out important findings. Importantly, a coding structure was adopted based on identified themes and sub-themes in the data which was presented in tabular form. A review of the identified themes were done, in comparison with the data sections from which these themes emerged to further ensure validity and accuracy. Changes were made where necessary. Thus the presentation of the findings reflect the themes and relevant quotes from the women.

\section{Results}

Socio-demographic characteristics and OOP payments by women

Three hundred and fifty-three (353) women who gave birth in health facilities took part in the quantitative aspect of the study. The mean age of the women was 27 years, with the youngest being 16 and the oldest 45 years. The majority of the women were married (96.3\%, $n=340$ ), practice Catholicism $(49.3 \%, n=174)$ and belong to the ethnic group "Kasem" $(62.6 \%, n=221)$. The age group $20-24$ had the highest percentage of women $(10.9 \%, n=10)$ who reported incurring OOP payments (Table 1). Incurring OOP payments was also common among women who were married $(9.1 \%, n=31)$, had no formal or basic education $(23.7 \%, n=27)$, farmers $(14.9 \%, n=18)$ and first time mothers $(8.4 \%, \mathrm{n}=10)$. Majority of the women $(68 \%, n=$ 240) gave birth in the district hospital. This was followed by CHPS compounds $(19.5 \%, n=69)$ and health centres $(11.9 \%, n=42)$.
Table 1 Socio-demographic characteristics and OOP payments by women

\begin{tabular}{|c|c|c|c|c|}
\hline \multirow[t]{3}{*}{ Variable } & & \multicolumn{3}{|c|}{$\begin{array}{l}\text { Incurred OOP Payments? } \\
N=353\end{array}$} \\
\hline & & \multirow{2}{*}{$\begin{array}{l}\text { Yes } \\
n(\%)\end{array}$} & \multirow{2}{*}{$\begin{array}{l}\text { No } \\
\text { n (\%) }\end{array}$} & \multirow{2}{*}{$\begin{array}{l}\text { Total } \\
\mathrm{n}(\%)\end{array}$} \\
\hline & & & & \\
\hline \multirow[t]{5}{*}{ Age } & $<20$ & $3(8.3)$ & $33(91.7)$ & $36(10.2)$ \\
\hline & $20-24$ & $10(10.9)$ & $81(89.1)$ & $91(25.8)$ \\
\hline & $25-29$ & $8(6.8)$ & $110(93.2)$ & $118(33.4)$ \\
\hline & 30- 39 & $7(7.0)$ & $93(93.0)$ & $100(28.3)$ \\
\hline & $40+$ & $4(50.0)$ & $4(50.0)$ & $8(2.3)$ \\
\hline \multirow[t]{2}{*}{ Marital status } & Single & $1(7.7)$ & $12(92.3)$ & $13(3.7)$ \\
\hline & Married & $31(9.1)$ & $309(90.9)$ & $340(96.3)$ \\
\hline \multirow{4}{*}{$\begin{array}{l}\text { Highest } \\
\text { educational level }\end{array}$} & No formal education & $6(12.8)$ & $41(87.2)$ & 47 (13.3) \\
\hline & Basic education & $21(10.9)$ & $172(89.1)$ & $193(54.7)$ \\
\hline & $\begin{array}{l}\text { Secondary/Technical } \\
\text { education }\end{array}$ & $2(3.1)$ & $62(96.9)$ & $64(18.1)$ \\
\hline & Tertiary & $3(6.1)$ & $46(93.9)$ & 49 (13.9) \\
\hline \multirow[t]{6}{*}{ Occupation } & Unemployed & $1(4.2)$ & $23(95.8)$ & $24(6.8)$ \\
\hline & Trader & $8(11.3)$ & $63(88.7)$ & $71(20.1)$ \\
\hline & Farmer & $18(14.9)$ & $103(85.1)$ & $121(34.3)$ \\
\hline & Public/Civil servant & $2(4.4)$ & 44 (95.6) & $46(13.0)$ \\
\hline & Student & $1(2.6)$ & $37(97.4)$ & $38(10.8)$ \\
\hline & Other & $2(3.8)$ & $51(96.2)$ & $53(15.0)$ \\
\hline \multirow{4}{*}{$\begin{array}{l}\text { Religious } \\
\text { background }\end{array}$} & Traditional & $4(6.7)$ & $13(93.3)$ & $17(4.8)$ \\
\hline & Catholic & $9(6.0)$ & $170(94.0)$ & $174(49.3)$ \\
\hline & Protestant & $16(12.6)$ & $118(87.4)$ & $134(37.9)$ \\
\hline & Muslim & $2(7.1)$ & $26(92.9)$ & $28(8.0)$ \\
\hline \multirow[t]{3}{*}{ Ethnicity } & Kasem & $15(6.8)$ & $206(93.2)$ & $221(62.6)$ \\
\hline & Nankam & $15(14.2)$ & $91(85.8)$ & $106(30.0)$ \\
\hline & Other & $2(7.7)$ & $24(92.3)$ & $26(7.4)$ \\
\hline \multirow{4}{*}{$\begin{array}{l}\text { Number } \\
\text { of births }\end{array}$} & 1 & $10(8.4)$ & 109 (91.6) & 119 (33.7) \\
\hline & 2 & $8(8.3)$ & 88 (91.7) & $96(27.2)$ \\
\hline & 3 & $4(5.7)$ & $66(94.3)$ & 70 (19.8) \\
\hline & 4 or more & $10(14.7)$ & $58(85.3)$ & 68 (19.3) \\
\hline
\end{tabular}

\section{Coverage of health expenses by the NHIS during childbirth}

In total, $69.4 \%(n=245)$ of the women who gave birth in health facilities perceived that the NHIS did not cover all the expenses incurred during childbirth. The women in the FGDs reported that they had made OOP payments for drugs and other supplies during childbirth despite these being covered by the NHIS. A woman said:

"I paid for my injection during pregnancy and when I delivered the drugs for the baby they wrote it for me to go and buy" (FGDs, woman). 
Apart from payments for drugs and other supplies, women were often given a prescribed list of items by health providers to purchase in preparation for childbirth. These items were to be used during childbirth and after, comprising of disinfectants, soaps, rubber pads, and clothing for newborns as the facilities lacked funds to purchase these items. Most of the women indicated that they bought these items for use during childbirth. A woman reported:

"They let you buy pad so that when you deliver they will use it, they will also let you buy detol [disinfectant] and all those things are not free. The pad is GHQ10 [US\$ 5.10] and the detol is GH45 [US\$2.50], meanwhile when you are pregnant you don't work" (FGDs, woman).

Women underwent financial strain to buy the prescribed items in preparation for childbirth. Women needed to exhaust their savings they would have made before pregnancy or rely on either their husbands or other relatives to purchase the items.

\section{Estimated OOP payments during childbirth}

The study estimated the OOP payments made for childbirth. The majority of women $(91.8 \%, n=324)$ incurred a mean OOP payment of GH4 48.60 (US\$24.70) for drugs (Table 2). The mean for direct and direct non-medical expenses was GH\$42.90 (US\$21.80) and GH\$34.20 (US\$17.40) respectively. Hospitalisation cost averaged GH\$4 (US\$2). The total OOP payments during childbirth was a mean of GH\$33.50 (US\$17).

\section{Impact of OOP payments on average monthly household income}

The mean for total direct medical expenses was estimated to be $7.1 \%$ of the average monthly household income of the region (Table 3). The overall mean for direct expenses associated with childbirth was $5.6 \%$ of the average monthly household income of the region. In addition, an estimated $36 \%(n=145)$ of the women incurred catastrophic OOP payments, using a $10 \%$ threshold of the average monthly household income.

Source of funds for OOP payments during childbirth.

Seventy-five percent $(n=264)$ of the women used savings for the payment of the expenses associated with childbirth,

Table 2 Estimated OOP payments during childbirth

\begin{tabular}{|c|c|c|c|c|c|c|}
\hline \multicolumn{3}{|l|}{ OOP expenditure incurred during childbirth } & \multirow{2}{*}{$\begin{array}{l}\text { Mean } \\
\text { GHÇ } \\
\text { (US\$) }\end{array}$} & \multirow{2}{*}{$\begin{array}{l}\text { Std dev } \\
\text { GHÇ } \\
\text { (US\$) }\end{array}$} & \multirow{2}{*}{$\begin{array}{l}\text { Min } \\
\text { GHÇ } \\
\text { (US\$) }\end{array}$} & \multirow{2}{*}{$\begin{array}{l}\text { Max } \\
\text { GHל } \\
\text { (US\$) }\end{array}$} \\
\hline & No. & $\%$ of women & & & & \\
\hline \multicolumn{7}{|l|}{ (a)Direct medical expenses (outpatient) } \\
\hline Folder fee (antenatal record) & 2 & 0.6 & $\begin{array}{l}11.50 \\
(5.80)\end{array}$ & $\begin{array}{l}3.53 \\
(1.80)\end{array}$ & $\begin{array}{l}9 \\
(4.60)\end{array}$ & $\begin{array}{l}14 \\
(7.10)\end{array}$ \\
\hline Consultation & - & - & - & - & - & - \\
\hline Laboratory test & 63 & 17.8 & $22.73(11.50)$ & $\begin{array}{l}45.35 \\
(23)\end{array}$ & $\begin{array}{l}5 \\
(2.50)\end{array}$ & $\begin{array}{l}300 \\
(152.20)\end{array}$ \\
\hline Drugs & 324 & 91.8 & $48.64(24.70)$ & $\begin{array}{l}88 \\
(44.70)\end{array}$ & $\begin{array}{l}3 \\
(1.50)\end{array}$ & $\begin{array}{l}876 \\
(444.50)\end{array}$ \\
\hline Blood transfusion & 9 & 2.5 & $31.27(15.90)$ & $23.16(11.80)$ & $\begin{array}{l}5 \\
(2.50)\end{array}$ & $\begin{array}{l}70 \\
(35.50)\end{array}$ \\
\hline Total direct medical expenses & 332 & 94.1 & $42.85(21.80)$ & $74.08(37.60)$ & $\begin{array}{l}3 \\
(1.50)\end{array}$ & $\begin{array}{l}876 \\
(444.48)\end{array}$ \\
\hline \multicolumn{7}{|l|}{ (b)Direct non-medical expenses } \\
\hline Food (meals) & 264 & 74.8 & $22.30(11.30)$ & $22.22(11.30)$ & $\begin{array}{l}1 \\
(0.50)\end{array}$ & $\begin{array}{l}110 \\
(88.51)\end{array}$ \\
\hline Transport & 105 & 29.7 & $23.44(11.90)$ & $\begin{array}{l}19.02 \\
(9.60)\end{array}$ & $\begin{array}{l}2 \\
(1.01)\end{array}$ & $\begin{array}{l}100 \\
(50.74)\end{array}$ \\
\hline Total direct non-medical expenses & 274 & 77.6 & 21.82(11.10) & $20.17(10.20)$ & $\begin{array}{l}1 \\
(0.50)\end{array}$ & $\begin{array}{l}110 \\
(88.51)\end{array}$ \\
\hline Total direct and direct non-medical expenses $(a+b)$ & 343 & 97.2 & $34.23(17.40)$ & $\begin{array}{l}57.04 \\
(28.90)\end{array}$ & $\begin{array}{l}4.5 \\
(2.28)\end{array}$ & $\begin{array}{l}876 \\
(444.48)\end{array}$ \\
\hline (c)Hospitalisation expenses (inpatient) & 33 & 9.3 & $\begin{array}{l}3.96 \\
(2)\end{array}$ & $\begin{array}{l}3.56 \\
(1.80)\end{array}$ & $\begin{array}{l}2 \\
(1.01)\end{array}$ & $\begin{array}{l}18 \\
(9.13)\end{array}$ \\
\hline (M) Overall direct expenses $(a+b+c)$ & 343 & 97.2 & $\begin{array}{l}33.53 \\
(17)\end{array}$ & $\begin{array}{l}56.98 \\
(28.90)\end{array}$ & $\begin{array}{l}3.5 \\
(1.77)\end{array}$ & $\begin{array}{l}876 \\
(444.48) 94\end{array}$ \\
\hline
\end{tabular}


Table 3 OOP payments as a percentage of average monthly household income

\begin{tabular}{ll}
\hline Average OOP payments & $\%$ of monthly household income \\
\hline Total direct medical expenses & $7.1 \%$ \\
Total direct non-medical expenses & $3.6 \%$ \\
Hospitalisation expenses & $0.7 \%$ \\
Overall direct OOP payments & $5.6 \%$ \\
\hline
\end{tabular}

whilst $19.0 \%(n=69)$ sold assets to finance the payments (Fig. 1).

The findings from the FGDs confirmed that household savings were used to meet the expenditure incurred during childbirth and in some cases, assets in the form of domestic animals and chicken were sold to finance the payments. A woman said:

"We used all our savings to pay for the cost when I went to the hospital for delivery" (FGD, woman).

The depletion of savings and sale of assets by women and their families would affect their economic welfare, especially the consumption of essential commodities.

\section{Discussion}

More than two-thirds $(69 \%, n=245)$ of women who gave birth in health facilities perceived the NHIS did not cover all the expenses incurred during childbirth. They had made OOP payments for drugs and other supplies during childbirth. The women had also bought items consisting of disinfectants, soaps, rubber pads and clothing for newborns. The overall mean for OOP payments during childbirth was GH\$33.50 (US\$17) and constituted 5.6\% of the average monthly household income for the Upper East region. Approximately, 36\% ( $n=145)$ of the women incurred catastrophic OOP payments, given a $10 \%$ threshold of the average monthly household income. Furthermore, 75 $\%(n=264)$ of the women used savings and 19\% $(n=69)$ sold assets to finance the payments.

\section{Buying of drugs and other supplies during childbirth}

Over two-thirds (69\%) of the women indicated that the NHIS did not cover all expenses and that direct OOP payments were made for drugs and other supplies. Findings from recent studies are consistent with our finding [36, 37]. A qualitative study in Morocco demonstrated that women and their families paid for drugs and other supplies during childbirth in three public hospitals, despite the existence of a fee exemption policy [38]. In Ghana, under an earlier fee exemption policy implemented in 2003, women and their families were found to have made payments for drugs and other services during childbirth [14, 39]. Inadequate government budgetary allocations affected the operations of the previous fee exemption policy [14]. However, the current policy is suffering a similar fate. The OOP payments occurred largely due to stock-outs of drugs and supplies caused by a delay in the reimbursement of health facilities by the NHIS. Consequently, health facilities were unable to procure drugs for dispensation and hence prescription forms were given out to women to purchase drugs out of health facilities. This problem is compounded for the smaller health facilities like the CHPS compounds and health centres with smaller budgets and limited internal generated funding. Another factor triggering the OOP payments is the prescription of drugs outside the essential drug list of the NHIS requiring women and their families to buy. Generally, any OOP payments affected the use of skilled attendance for childbirth [5-7].

\section{Buying of other items for childbirth}

Women and their families were prescribed items comprising of disinfectants, soaps, rubber pads and clothing for newborns to be acquired for use during childbirth. Other studies under fee exemptions policies have had similar findings $[24,40]$. Since these prescribed items are not covered by the NHIS and hence women and their families would have to provide them from their own resources, their procurement could affect the utilisation of skilled attendance at childbirth, especially for poor women. Women, especially the poor who cannot afford to buy such items may not be motivated to visit formal health facilities for childbirth and would prefer to give birth at home or elsewhere not requiring the purchase of such items [40]. This might explain why poor women as compared to rich ones were underutilising maternal health services in Ghana [41].

\section{Mean cost for OOP payments during childbirth}

The estimated mean for OOP payments during childbirth was GH\$33.50 (US\$17), conforming to previous studies [21, 23, 37, 42-44]. For instance, in rural Tanzania, Kruk et al. reported that $73.3 \%$ of women still incurred OOP payments despite a free childbirth policy [21]. The average cost incurred during childbirth in her study was US\$5.00 [21]. Another study in North Western Nigeria showed that women and their families spent an average of US\$3.00 for normal childbirth [42]. The high costs of drugs might help explain the high mean cost for childbirth in our study. A mean cost of GH\$48.6 (US\$24.7) was recorded for drugs alone in our study. Compared with most countries in the world, the cost of drugs are very high in Ghana [45]. Given this background, women and their families may be discouraged from using skilled attendance at childbirth, if consistently they have to buy drugs at a very high cost.

Additionally, the overall mean OOP payments recorded during childbirth is considered as high, in the midst of the free maternal care policy. The finding confirmed a study 


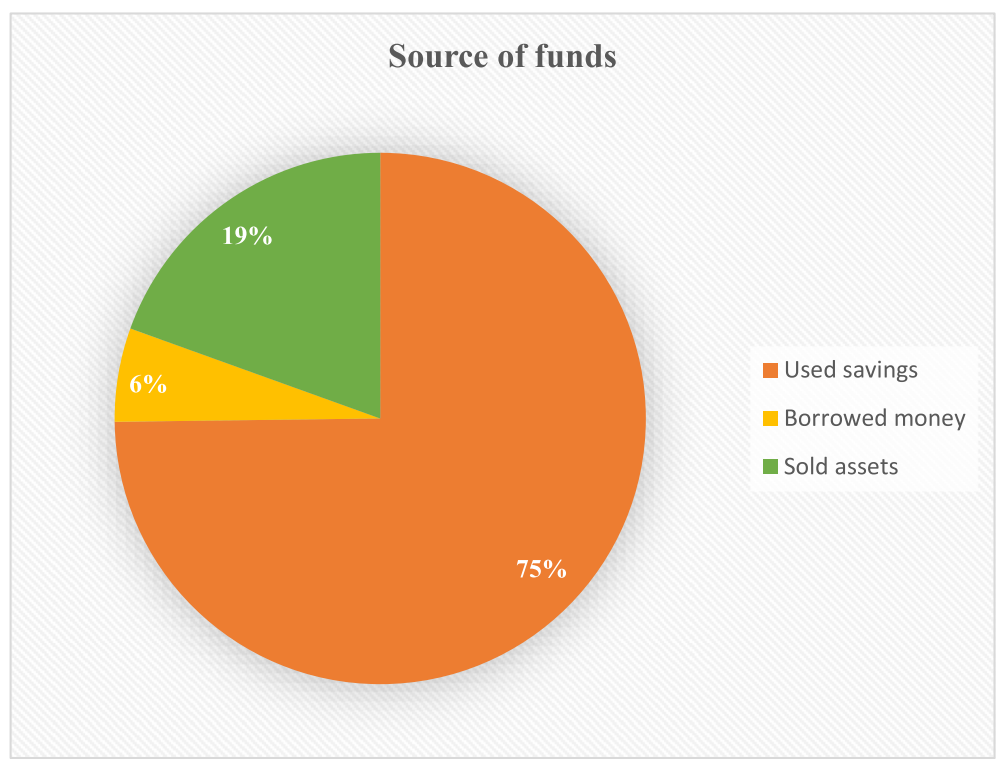

Fig. 1 Source of funds for OOP payments during childbirth

in three African countries which demonstrated that OOP payments for maternal health services constituted a significant percentage of household income, despite some interventional policies being in place in those study areas [46]. A 5.6\% expenditure for childbirth alone, could adversely affect the welfare of households in terms of their expenditure on other necessities. This is further supported by the finding that $36 \%$ of the women incurred catastrophic OOP payments. The women and their families would have to forgo the consumption of some essentials, for using skilled attendants. This is a de-motivator for the utilisation of skilled attendance for childbirth and the drive for achieving universal health coverage. But universal health coverage is taken as a top priority for the new Director-General of the World Health Organisation, Tedros Adhanom Ghebreyesus, who declared in his first press conference that "All roads should lead to universal health coverage" [47].

\section{Use of savings and sale of assets for the OOP payments}

Despite the existence of the free maternal care policy, our study indicated that $75 \%$ of the women who made OOP payments used savings, with $19 \%$ of them selling assets to finance the payments. The finding is consistent with literature [21, 33, 37, 38, 48]. In rural Ethiopia, households resorted to borrowing from relatives and friends and the sale of assets to meet health expenditure for childbirth [48]. Households in rural Bangladesh also used income and savings to make payments for childbirth services [33]. Given the implementation of the policy, women are exempted from paying some of the costs associated with the use of maternal health services, however the recorded payments is seen as burdensome since some coping strategies (savings and sale of assets) had to be adopted. The use of savings as well as sale of assets by women and families for payment of maternal health services could erode the asset base of families. It could also increase the vulnerability of such households to more economic challenges. Thus the systemic challenges requiring the need for OOP payments by the women and families has to be re-examined in order to prevent the perpetuation of the OOP payments. There is the need for health facilities to be adequately resourced, especially under the NHIS. This would minimise or eliminate OOP payments and subsequently promote the use of skilled attendance at childbirth, leading to reduced maternal mortality.

\section{Study limitations}

The study has shown that OOP payments existed during childbirth despite the operations of the free maternal care policy, however, some limitations of the study must be noted. Firstly, since the interviews were carried out after the discharge of women and family members from health facilities to go home, there is the possibility of recall bias, especially on costs. Details of health payments might not be accurately recollected and given out during the interviews. Secondly, the study did not measure the opportunity cost (lost income for time spent seeking health care) associated with the use of skilled attendance during childbirth. These costs were not determined due to the challenges involved in their quantification. The exclusion of opportunity cost affects the overall mean for OOP payments and this should be noted when reading this paper. The study was conducted in only one municipality. There are a total of 216 metropolitan, municipal and district areas in Ghana. As such, the results might not be 
generalisable to the rest of Ghana, although they would be reflective of many similar regions in Ghana and across Africa.

\section{Conclusion}

The free maternal care policy has not been fully effective in eliminating financial barriers associated with the utilisation of skilled attendance at childbirth. Women and their families continued to make OOP payments for drugs, supplies and other prescribed items during childbirth. This comes in the face of systemic challenges, particularly the delay in reimbursement by the NHIS, leading to stock-outs of drugs and supplies for health facilities. The OOP payments impacted the welfare of the women and households as they used savings and sale of assets to meet the payments. There is the need to re-examine the reimbursement of health facilities by the NHIS in order to prevent shortage of funding to health facilities. When health facilities are well resourced, OOP payments would be reduced or eliminated, leading to increased utilisation of skilled attendance at childbirth and ultimately reducing maternal mortality and the achievement of universal health coverage in the long-term.

\section{Abbreviations}

FGDs: Focus Group Discussions; NHIS: National Health Insurance Scheme; OOP: Out of Pocket

\section{Acknowledgements}

We are grateful to the participants for taking part in the study. Thank you!

\section{Funding}

The University of Technology Sydney (UTS) awarded two scholarships (UTS International Research Scholarship and UTS President's Scholarship) to enable the first author pursue a doctoral degree in UTS. The UTS WHO Collaborating Centre in Nursing, Midwifery and Health also provided a travel award for data collection for the PhD.

\section{Availability of data and materials}

The manuscript is a product of a PhD project. The data is not publicly available. However, upon reasonable request, the data will be available from the corresponding author.

\section{Authors' contributions}

PAD AYW CSEH conceived and conceptualized the study. PAD collected and analysed the data and wrote the manuscript. AYW and CSEH carried out the critical review. All authors read and approved the final version of the manuscript.

\section{Ethics approval and consent to participate}

The Ethical Review Board of the Navrongo Health Research Centre, Ghana (NHRCIRB217) and the Human Research Ethics Committee of the University of Technology Sydney (ETH16-0263) approved for the conduct of the study. Informed consent was obtained from all participants.

\section{Consent for publication}

Written informed consent was obtained from the patient for publication of this case report and accompanying images.

\section{Competing interests}

The authors declare that they have no competing interests.

\section{Publisher's Note}

Springer Nature remains neutral with regard to jurisdictional claims in published maps and institutional affiliations.

Received: 4 August 2017 Accepted: 9 November 2017

Published online: 22 November 2017

\section{References}

1. UNICEF. UNICEF data: monitoring the situation of children and women: UNICEF; 2016

2. Campbell OMR, Graham WJ. Strategies for reducing maternal mortality: getting on with what works. Lancet. 2006;368(9543):1284-99. doi.10.1016/ S0140-6736(06)69381-1

3. IMCIBO. Improving birth outcomes: meeting the challenge in the developing world. In: Bale JR, Stoll BJ, Lucas AO, editors. Reducing maternal mortality and morbidity. 2. Washington: National Academies Press (US); 2003.

4. GSS. Ghana poverty mapping report. Accra: Ghana Statistical Service; 2015.

5. WHO. The world health report 2010. Health systems financing: the path to universal coverage. Geneva: World Health Organization. p. 2010.

6. Shahrawat R, Rao K. Insured yet vulnerable: out-of-pocket payments and India's poor. Health Policy Plan. 2012;27(3):213-21.

7. Saksena P, Hsu J, Evans DB. Financial risk protection and universal health coverage: evidence and measurement challenges. PLoS Med. 2014;11(9):e1001701. doi.10.1371/journal.pmed.1001701. PubMed PMID: PMC4171370

8. Asante FA, Chikwama C, Daniels A, Armar-Klemesu M. Evaluating the economic outcomes of the policy of fee exemption for maternal delivery Care in Ghana. Ghana Medical Journal. 2007;41(3):110-7. PubMed PMID: PMC2279082

9. Xiao S, Yan H, Shen Y, Dang S, Hemminki E, Wang D, et al. Utilization of delivery care among rural women in china: does the health insurance make a difference? A cross-sectional study. BMC Public Health. 2010;10(1):695. doi.10.1186/1471-2458-10-695.

10. Ridde V, Agier I, Jahn A, Mueller O, Tiendrebeogo J, Ye M, et al. The impact of user fee removal policies on household out-of-pocket spending: evidence against the inverse equity hypothesis from a population based study in Burkina Faso. Eur J Health Econ. 2015;16(1):55-64. doi.10.1007/ s10198-013-0553-5. Epub 201e4/01/15. PubMed PMID: 24414280

11. Masiye F, Kaonga O, Kirigia JM. Does user fee removal policy provide financial protection from catastrophic health care payments? Evidence from Zambia. PLoS One. 2016;11(1):e0146508. doi.10.1371/journal.pone.0146508.

12. Witter S, Boukhalfa C, Cresswell JA, Daou Z, Filippi V, Ganaba R, et al. Cost and impact of policies to remove and reduce fees for obstetric care in Benin, Burkina Faso, Mali and Morocco. Int J Equity Health. 2016;15:123. doi.10.1186/s12939-016-0412-y. PubMed PMID: PMC4970227

13. Hatt LE, Makinen M, Madhavan S, Conlon CM. Effects of user fee exemptions on the provision and use of maternal health services: a review of literature. J Health Popul Nutr. 2013;31(4 Suppl 2):S67-80. PubMed PMID: PMC4021702

14. Witter S, Adjei S. Start-stop funding, its causes and consequences: a case study of the delivery exemptions policy in Ghana. Int J Health Plann Manag. 2007;22(2):133-43. doi.10.1002/hpm.867. Epub 2007/07/12. PubMed PMID: 17623355

15. Dzakpasu S, Powell-Jackson T, Campbell OMR. Impact of user fees on maternal health service utilization and related health outcomes: a systematic review. Health Policy Plan. 2013; doi.10.1093/heapol/czs142.

16. Dzakpasu S, Soremekun S, Manu A, ten Asbroek G, Tawiah C, Hurt L, et al. Impact of free delivery care on health facility delivery and insurance coverage in Ghana's Brong Ahafo region. PLoS One. 2012;7(11):e49430. doi.10.1371/journal.pone.0049430.

17. Singh K, Osei-Akoto I, Otchere F, Sodzi-Tettey S, Barrington C, Huang C, et al. Ghana's National Health insurance scheme and maternal and child health: a mixed methods study. BMC Health Serv Res. 2015;15(108).

18. Brugiavini A, Pace N. Extending health insurance in Ghana: effects of the National Health Insurance Scheme on maternity care. Heal Econ Rev 2016;6:7. doi: doi.10.1186/s13561-016-0083-9. PubMed PMID: PMC4749513.

19. Leone T, Cetorelli V, Neal S, Matthews Z. Financial accessibility and user fee reforms for maternal healthcare in five sub-Saharan countries: a quasi-experimental analysis. BMJ Open. 2016;6(1) doi.10.1136/bmjopen-2015-009692.

20. Nahar S, Costello A. The hidden cost of 'free' maternity care in Dhaka. Bangladesh Health Policy Plan. 1998;13(4):417-22. Epub 1999/05/27. PubMed PMID: 10346033 
21. Kruk ME, Mbaruku G, Rockers PC, Galea S. User fee exemptions are not enough: out-of-pocket payments for 'free' delivery services in rural Tanzania. Tropical Med Int Health. 2008;13(12):1442-51. doi.10.1111/j.1365-3156.2008.02173.x.

22. Prinja S, Bahuguna P, Gupta R, Sharma A, Rana SK, Kumar R. Coverage and financial risk protection for institutional delivery: how universal is provision of maternal health Care in India? PLoS One. 2015;10(9):e0137315. doi.10.1371/journal.pone.0137315.

23. Issac A, Chatterjee S, Srivastava A, Bhattacharyya S. Out of pocket expenditure to deliver at public health facilities in India: a cross sectional analysis. Reprod Health. 2016;13(1):99. doi.10.1186/s12978-016-0221-1. PubMed PMID: PMC4997742

24. Acharya J, Kaehler N, Marahatta SB, Mishra SR, Subedi S, Adhikari B. Hidden costs of hospital based delivery from two tertiary hospitals in western Nepal. PLoS One. 2016;11(6):e0157746. doi.10.1371/journal.pone.0157746.

25. Acharya J. Are free maternity services completely free of costs? Osong Public Health and Research Perspectives. 2016;7(1):26-31. doi.10.1016/j.phrp.2015.11.002.

26. Dalaba MA, Akweongo P, Aborigo RA, Saronga HP, Williams J, Aninanya GA, et al. Cost to households in treating maternal complications in northern Ghana: a cross sectional study. BMC Health Serv Res. 2015;15(1):34 doi.10.1186/s12913-014-0659-1

27. Creswell JW. Research design: qualitative, quantitative and mixed methods approaches. 4th ed. Washington: SAGE Publication Inc.; 2014.

28. GSS. Ghana living standards survey round 6 (GLSS 6): main report. Accra: Ghana Statistical Services; 2014

29. Gorstein J, Sullivan KM, Parvanta I, Begin F. Indicators and Methods for Cross-Sectional Surveys of Vitamin and Mineral Status of Populations. The Micronutrient Initiative (Ottawa) and the Centers for Disease Control and Prevention (Atlanta), 2007

30. Dalinjong PA, Wang AY, Homer CS. Has the free maternal health policy eliminated out of pocket payments for maternal health services? Views of women, health providers and insurance managers in northern Ghana. PLoS One. 2017. doi:10.1371/journal.pone.0184830.

31. Amaya-Lara JL. Catastrophic expenditure due to out-of-pocket health payments and its determinants in Colombian households. Int J Equity Health. 2016;15(1):182. doi.10.1186/s12939-016-0472-z.

32. Borghi J, Sabina N, Blum LS, Hoque ME, Ronsmans C. Household costs of healthcare during pregnancy, delivery, and the postpartum period: a case study from Matlab, Bangladesh. J Health Popul Nutr. 2006;24(4):446-55. PubMed PMID: PMC3001148

33. Hoque ME, Dasgupta SK, Naznin E, Al MA. Household coping strategies for delivery and related healthcare cost: findings from rural Bangladesh. Tropical Med Int Health. 2015;20(10):1368-75. doi.10.1111/tmi.12546

34. Goli S, Moradhvaj RA, Shruti PJ. High spending on maternity Care in India: what are the factors explaining it? PLoS One. 2016;11(6):e0156437. doi.10.1371/journal.pone.0156437

35. Adam W. Measuring financial protection in health. World Bank policy research working paper no 4554: World Bank; 2008.

36. Lange IL, Kanhonou L, Goufodji S, Ronsmans C, Filippi V. The costs of 'free': experiences of facility-based childbirth after Benin's caesarean section exemption policy. Social science \& medicine (1982). 2016;168:53-62. doi.10.1016/j.socscimed.2016.09.008. Epub 2016/09/18.PubMed PMID: 27639052

37. Boukhalfa C, Abouchadi S, Cunden N, Witter S. The free delivery and caesarean policy in Morocco: how much do households still pay? Tropical Med Int Health. 2016;21(2):245-52. doi.10.1111/tmi.12638. Epub 2015/11/21. PubMed PMID: 26584606

38. Bennis I, De Brouwere V. Fee exemption for caesarean section in Morocco. Archives of Public Health. 2012;70(1):3. doi.10.1186/0778-7367-70-3. PubMed PMID: PMC3415113

39. Witter S, Adjei S. Start-stop funding, its causes and consequences: a case study of the delivery exemptions policy in Ghana. Int J Health Plann Manag. 2007;22(2):133-43.

40. Women's Dignity, International C. 'We have no choice' facility-based childbirth: the perceptions and experiences of Tanzanian women, health workers, and traditional birth attendants, Tanzania. 2008.

41. Johnson FA, Frempong-Ainguah F, Padmadas SS. Two decades of maternity care fee exemption policies in Ghana: have they benefited the poor? Health Policy Plan. 2016;31(1):46-55. doi.10.1093/heapol/czv017
42. Kalu-Umeh NN, Sambo MN, Idris SH, Kurfi AM. Costs and patterns of financing maternal health Care Services in Rural Communities in northern Nigeria: evidence for designing National fee Exemption Policy. Int J MCH and AIDS. 2013;2(1):163-72. Epub 2013/01/01. PubMed PMID: 27621969; PubMed Central PMCID: PMCPMC4948141

43. Sidney K, Salazar M, Marrone G, Diwan V, DeCosta A, Lindholm L. Out-ofpocket expenditures for childbirth in the context of the Janani Suraksha Yojana (JSY) cash transfer program to promote facility births: who pays and how much? Studies from Madhya Pradesh, India. Int J Equity Health. 2016; 15:71. doi.10.1186/s12939-016-0362-4. Epub 2016/05/05. PubMed PMID: 27142657; PubMed Central PMCID: PMCPMC4855911

44. Adamu H, Isa AY, Zubairu S. Expenditure on emergency obstetric Care in a Federal Tertiary Institution in Nigeria. Journal of Womens Health Care. 2013; 2(4):134.

45. Saleh K. The health sector in Ghana: a comprehensive assessment. Washington: World Bank; 2013.

46. Perkins M, Brazier E, Themmen E, Bassane B, Diallo D, Mutunga A, et al. Out-of-pocket costs for facility-based maternity care in three African countries. Health Policy Plan. 2009;24(4):289-300. doi.10.1093/heapol/czp013. PubMed PMID: PMC2699243

47. Murphy T. Global Health: universal health coverage is top priority for new WHO chief. Humanosphere. 2017;

48. Akalu T, Guda A, Tamiru M, Haile MD. Examining out of pocket payments for maternal health in rural Ethiopia: paradox of free health care unaffordability. Ethiop J Health Dev. 2012;26(1):251-7.

\section{Submit your manuscript to a SpringerOpen ${ }^{\circ}$ journal and benefit from:}

- Convenient online submission

- Rigorous peer review

- Open access: articles freely available online

- High visibility within the field

- Retaining the copyright to your article

Submit your next manuscript at $>$ springeropen.com 